\section{Bankruptey risk prediction models based on artificial neural networks}

Doina PRODAN-PALADE, Alexandru loan Cuza University, lasi, Romania, E-mail:doina_prodan_palade@bau.edu.jo

\section{Alostract}

The purpose of this research is to study the ability of artificial neural networks to forecast the companies' risk of financial distress. We predicted the bankruptcy risk using the associated financial ratios (overall liquidity ratio and the overall solvency ratio) and two artificial neural network models based on the backpropagation algorithm. The proposed models were implemented and tested using the PyBrain software and have been applied to 55 companies listed on the Bucharest Stock Exchange during 2010-2014. After a total of 19,944 iterations for the learning stage, the two algorithms converged and the errors obtained during the tests reached the fixed target. The empirical results showed that the artificial neural network models are efficient and reliable in detecting the risk of bankruptcy. The artificial neural networks are very useful in economic analysis when the complexity of data makes it difficult to implement functions that proper describe the link between economic variables. The use of the neural networks method for predicting the risk of bankruptcy is less common in Romania. This study intends to fill this gap in the literature and we believe it could be of interest not only for the companies listed on the stock exchange, but also for investors, shareholders and banks.

Keywords: Artificial Neural Networks; backpropagation; bankruptcy risk; overall liquidity ratio; overall solvency ratio

JEL Classification: M41, C53, G33

To cite this article:

Prodan-Palade, D. (2017), Bankruptcy risk prediction models based on artificial neural networks, Audit Financiar, vol. XV, no. 3(147)/2017, pp. 418-429,

DOI: $10.20869 / A U D I T F / 2017 / 147 / 418$

To link to this article:

http://dx.doi.org/10.20869/AUDITF/2017/147/418

Received: 15.07.2016

Revised: 13.12 .2016

Accepted: 20.12.2016 


\section{Introduction}

For enterprises' competitiveness in the fast changing economic environment of the international market, the accurate prediction of the financial risk is one of the key factors. The globalization of the financial markets shortened the time that policy makers should respond and take decisions (Aydin and Cavdar, 2015). Meanwhile, the interconnections between the financial institutions magnify the consequences of the economic crises (Glasserman and Young, 2013). As a result, there is a high request for accurate forecasting of the firms' financial distress and bankruptcy risk. The accurate predicting models help the policy makers to take the right decisions and to reduce the trading risk (Airinei and Berta, 2012). The recent financial crisis emphasized the weakness of the traditional statistical models. If there is a significant difference between the predicted and the audited profits, the companies would lose their credibility to investors and all stakeholders (Bunget et al., 2014). The data analysis can be performed using diverse techniques such as descriptive statistics, regression analysis, data mining, fuzzy logic algorithms or neural networks models.

\section{Lïterature review on applying artificial neural networks to business}

In a healthy economy there is a high request for a proper distribution of resources in the financial markets. Nowadays firms are complex systems, the economic environment is changing very fast and the managerial functions can no longer be performed by a single person. Managers have shorter time for taking decisions and evaluation of the companies became a very difficult issue, requesting a good qualitative and risk oriented analysis. Accurate results require suitable accounting data (Bunget, 2009), including qualitative variables, such as political and environmental indicators, calendar anomalies and business cycles (Tjung et al., 2012) as well as the use of proper statistical methods (Vallini et al., 2009). The research papers showed that ANNs can forecast the companies' financial performance with a high accuracy.
Salama and Omar (2014) developed and tested a backpropagation ANN model that could detect and predict fraudulent financial reporting. Shang et al. (2015) studied the financial risk forewarning of the Growth Enterprises Market (GEM) companies belonging to the Chinese Strategic Emerging Industries (SEI). They used the stepwise regression model and backpropagation neural network (BPNN) model. The empirical results showed that BPNN can better predict the financial risk than the regression model. They found that the accuracy of NN and other Artificial Intelligence (AI) methods is superior to that of traditional statistical methods. Compared to other models of predicting stock prices, the empirical studies showed that ANNs have the best performance (Ardebili et al., 2015).

Trying to discover complex patterns in data by using multiple discriminant analysis (MDA) and ANN, Coats and Fant (1993) found that NN approach is more accurate and effective than MDA. Yildiz and Yezegel (2010) performed a fundamental analysis trading strategy on a sample of firms traded in the New York (NYSE), American (AMEX) and NASDAQ stock exchanges. They showed that the neural networks have the ability to predict future returns in NYSE/AMEX/NASDAQ securities for the period 1990-2005.

Traditional statistical models are valid only under some restrictive assumptions such as linearity, the normal distribution of data and the independence of predictor variables (Alborzi et al., 2013; Yildiz and Yezegel, 2010). As a result, they do not accurately reflect the economic processes and environment. They cannot inductively learn from new data dynamically, thus greatly affecting the forecasting accuracy (Khademolqorani and Farimah, 2015).

Using linear regression and ANN methods, Ahangar et al. (2015) estimated the stock price of the companies listed on Tehran Stock Exchange. Comparing the performance of the two algorithms, the empirical results showed that ANNs are more efficient than the linear regression model. Hu et al. (2012) used a sample of daily oil prices from Brent, West Texas Intermediate (WTI), Dubai, and International Petroleum Exchange (IPE) between 1990 and 2005 and tested the prediction accuracy of ANNs for the prices of crude oil futures. During the empirical tests they used Elman recurrent neural 
network (ERNN), recurrent fuzzy neural network (RFNN), and Multilayer Perceptron (MLP). The results showed that the RFNN has the best predictive power and the MLP has the worst one. They also found that the predictive power of the ANNs is better when the training time increases.

\section{Backuronagation neural networks}

The human brain is endowed at birth with the ability to process information and perform complex activities such as motion control, pattern recognition, interaction with the environment and the ability to learn from experience. It is made of neurons which transform the inputs into outputs. Artificial Intelligence (Al) stores knowledge, being able to use it to solve problems and it acquires new knowledge from experience. For this purpose, it uses a language made of symbols that helps to seek solutions and solve the given problems. The semantic expressions used in Al are complex, syntactic and rule-based, being similar to the natural language.

As part of the Artificial Intelligence, the neural networks are systems that use approximation methods based on the learning process. Neural computing is a discipline that attempts to simulate the functioning of the human brain using computer systems (Aydin, 2015), algorithms, and combining knowledge from different disciplines such as biology, chemistry, physics, mathematics, and economics. An important feature of these networks is that they are capable of self-organization and therefore, to solve the problems, they do not require the implementation of some programs with powerful algorithms. Instead, they need a training phase for building knowledge using some specific data sets.

After storing the knowledge, through a process of "thinking" that mimics human reasoning, they are able to solve very complex problems. Thus, starting from a training set containing a lot of examples that are given as input values, the neural networks create a specific model based on the given problem. Other approaches are the neuro-fuzzy systems and the hybrid models based on genetic, fuzzy or neural networks (Pradhan et al., 2015). They are based on the fuzzification - defuzzification process applied to the inputs and outputs of the neural network, bringing the artificial reasoning closer to the human one.

Due to their universality, the application fields of neural networks are very diverse, from the natural sciences, industry, agriculture, arts, and entertainment. With the help of neural networks, the analyses and predictions for the management of companies and the capital markets can be performed with high accuracy. Among the most frequently used applications include natural language processing, image processing, pattern recognition, handwriting interpretation, robotics and modeling in economy and finance.

During the business activities, highly difficult problems can be solved by experts, namely professionals who have extensive experience. The Artificial Neural Networks (ANN) can also gain experience after performing some iterative learning processes. They are able to solve the highly complex problems of the economic environment, without resorting to the knowledge of specialists.

\section{Basic principles of neural computation}

The neural computations are based on mathematical models taken from neurobiology, having three main components:

- Computation units;

- Layers made of computation units;

- Rules for changing the intensities of connections between the computation units.

The neural computing concept was launched in 1943 in "A Logical Calculus of Ideas Immanent in Nervous Activity" published by teachers McCulloch and. In 1969, Minsky and Papert presented the neural model made of layers of neurons that transmit information from input to output through connections similar to the synaptic connections. The most important step in the developing of the neuronal networks is the implementation of learning by the backpropagation method, discovered by Werbos in 1974, which has been still used. Depending on how the neurons are connected, there are three types of networks: directly connected, backpropagation (BP) or recurrent. BP networks are common in many applications. They 
use a multilayer neural architecture that have at least one hidden layer of neurons and apply algorithms to minimize the function error. The activation function of the hidden layers is a logistic function of the following form (Enăchescu, 2009):

$$
f(x)=1 /\left(1+e^{\wedge}(-x)\right)
$$

The number of nodes in the hidden layer can be determined using the trial and error method or by the formula method. The most used formulas are (Shang et al., 2015):

$$
\begin{gathered}
m=\sqrt{n l} \\
m=\log _{2} n \\
m=\sqrt{n+1}+a ; a=\text { constant, } a \in[0,1]
\end{gathered}
$$

Where:

- $m=$ number of nodes in the hidden layer

- $n=$ number of nodes in the input layer

- $I=$ number of nodes in the output layer

The neural networks can be used for prediction, classification, conceptualization, data filtering and association. To perform the evaluation of the model, the data set is usually split into three sets: training set, validation set and test set (Badea, 2013). The accuracy of ANNs forecasts depends on some factors with significant impact on their performance, including the selection of input variables, the network architecture, and the quantity of data used for the training step (Walczak, 2001). Despite other programming methods, the artificial neural network has the ability to learn. Learning in a neural system is based on two steps. The first step is designed to train and to accumulate the knowledge. In the next step they perform functional modifications to the neural network nodes that modify the internal structure. A neuron or node has several input signals and produce a single output signal, each of the entries having assigned a specific synaptic weight.

During the learning process, the neurons change the weights of the input variables, depending on the errors between the target output and the predicted output of the network. Based on the weights of the neural connections, the algorithm synthesizes a specific model to solve the problem. Through this mechanism, the neural networks can perform complex tasks, for which the implementation of classical algorithms for processing would be very difficult.

In the typical structure of a backpropagation (BP) network type, the neurons are connected in multiple layers. The first layer receives the input values, the last layer network provides the output, and between these two layers there could be one or more hidden layers. Each computing element of a neural network is assigned a combination of inputs that is turned into an output value, based on the previously stored knowledge. During the training-learning process, the network receives a large number of input values and adjusts the weights using the BP algorithm. Based on the inputs, the network of artificial neurons identifies certain patterns and connections and gets an output that will be compared with some known values, called target values. The errors computed as the difference between the outputs of the network and target values flows back through the hidden layers of the network. The process repeats until the difference between the output value of the network and the target one reaches a minimum set a priori.

One drawback of these systems is the time interval required to load and store knowledge. Another problem is the large amount of input information necessary for the learning process (Kaastra and Boyd, 1996). In order to provide a proper solution, the system should receive complete details of the task. As the large amount of input data needed to be processed is time and resource consuming, the researchers are currently seeking to develop new training systems that can operate efficiently with a smaller amount of initial knowledge.

\section{Empirical study using neural networks to predict bankruntey risk}

The paper proposes two supervised ANNs model based on the backpropagation method for predicting the risk of bankruptcy using the associated financial ratios. The learning process is supervised, based on a sample of inputs and outputs. The supervised learning includes error-correction process, reinforcement learning, stochastic learning and error-convergence (Salama and Omar, 2014). The error convergence concept means that the differences between the target 
and the computed output values must be minimized. For this purpose, the algorithm changes the weights and creates the appropriate model. The neural network models predict the risk of bankruptcy based on the analysis of past events of the corporate activity (Prodan-Palade, 2016).

Romania is an emerging country that has a dynamic market and presents numerous opportunities for the international economic environment, along with more risks than other developed markets. In the last 26 years our country has experienced many transformations, transitioning from a centralized to a market economy. Regarding the dynamic business environment, according to the National Trade Registry Office, on 31 December 2015 in Romania there were a number of 773,781 active legal entities. During the same year, a total of 10,269 entities have involved into insolvency proceedings, representing a rate of $1.33 \%$ of active entities, down from the previous period with $50.38 \%$, while $2.29 \%$, respectively a number of 17,698 entities had suspended their activity, meaning an increase by $12.10 \%$ compared to 2014 .

Many of the entities listed on the Bucharest Stock Exchange (BSE) are in their first stage of development and require much investment, the bank loans being among the most important sources of funding for the Romanian companies. The problems of liquidity and debt repayment capacity are essential in analyzing their financial balance. Therefore, we consider necessary the building of a base knowledge and the formalization of prediction models for liquidity and solvency of the entities, based on the concept of neural networks.

Our research proposes two prediction models, one designed for prediction the overall liquidity ratio and the other designed for prediction the overall solvency ratio. The two indicators are considered to be the main ones in analyzing the financial stability of an entity. The overall liquidity ratio is expressed by the fixed assets ratio, the global financial autonomy ratio, acid test ratio, the cash ratio and the profit ratio. The overall solvency ratio is expressed by the fixed assets ratio, the global financial autonomy ratio and the overall liquidity ratio (Prodan-Palade, 2016).

The sample consists of 55 entities listed on BSE during 2010-2014 from the manufacturing industry. The accounting information used for determining the financial indicators was extracted from the companies' annual reports published on the website of the stock exchange.

The application has three working stages for training, testing and prediction. During the training stage the network is learning, based on the information provided at the input and identifies a particular model. For the first stage we used the accounting input data corresponding to the financial exercises between 2010 and 2013. The predicting and testing the accuracy of the algorithm were performed using accounting data for the year 2014.

\subsection{Building a neural network model for the prediction of overall liquidity ratio}

The concept of liquidity expresses the company's ability to pay its short-term debt obligations. It is the coverage level of short-term debts by current assets. The acceptable values for this ratio vary from one industry to another. The literature recommends a general value more than 1 . On the other hand, there are certain cases where a too high overall liquidity ratio (current ratio), for example much more than 2, may signify the presence of inventories and receivables that consume significant financial resources and therefore being a negative sign for the company. Hence, in the prediction model of overall liquidity ratio we considered useful to include the acid test ratio that takes into account the inventory levels of the entity.

The architecture of this ANN is shown in Figure no. 1. The proposed model consists of:

- 5 neurons in the layer 1 (the input layer);

- 19 neurons in the layer 2 (the hidden layer);

- 1 neuron in the layer 3 (the output layer). 


\section{Figure no. 1. The neural network model to predict the overall liquidity ratio}

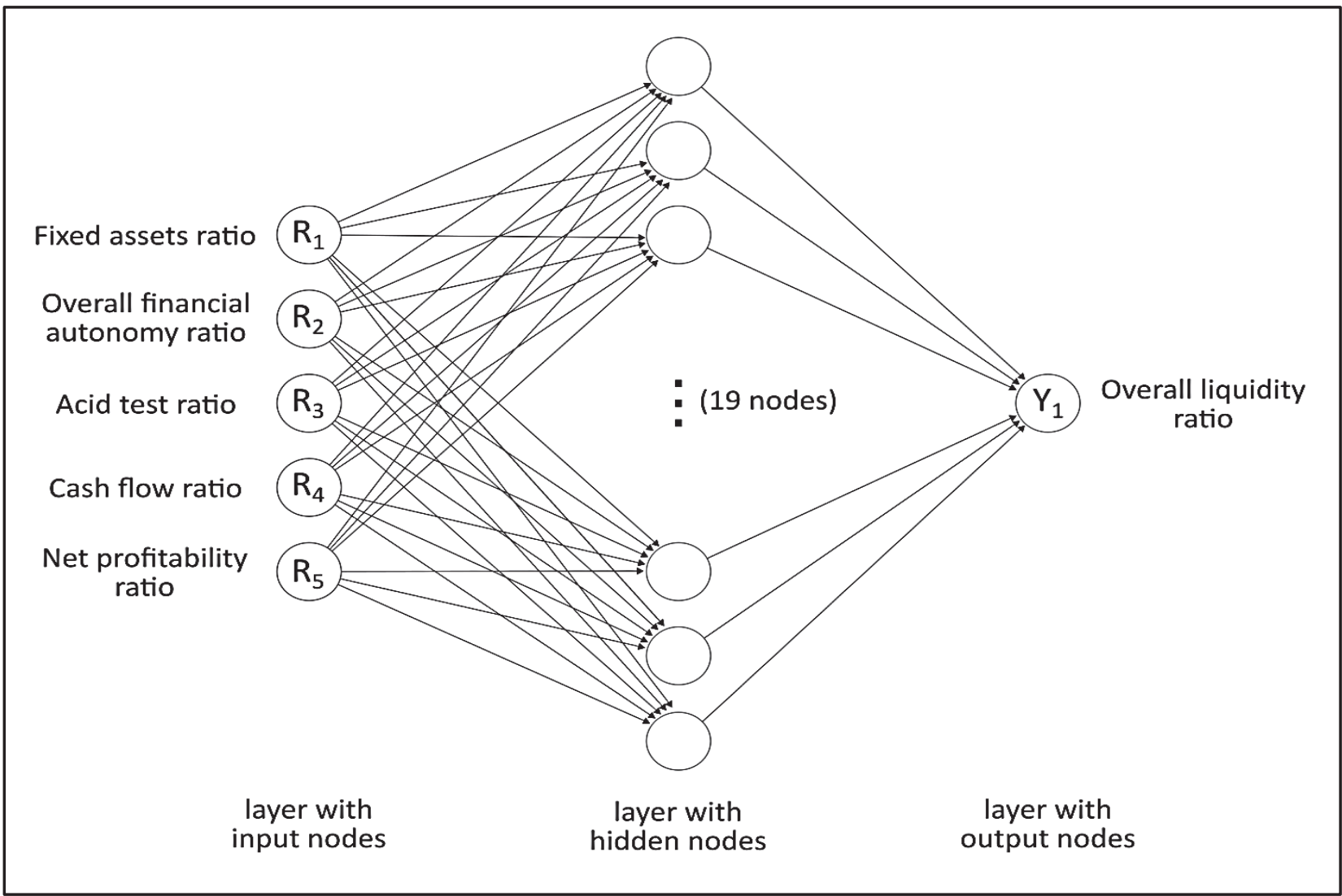

Source: own processing

Where:

- $\mathrm{R} 1$ (Fixed assets ratio) $=$ fixed assets/total assets

- R2 (Overall financial autonomy ratio) $=$ shareholders' equity/total passive

- R3 (Acid test ratio or Quick ratio = (current assets inventory)/current liabilities

- R4 (Cash flow ratio) $=$ net cash flow/current liabilities

- $\mathrm{R} 5$ (Net profitability ratio) = after-tax profit $/$ net turnover

- $\quad$ Y1 (Overall liquidity ratio or Current ratio) $=$ current assets/current liabilities

Considering:

- $R_{i} ; i=\overline{1,5}$, the input neurons;

- $H_{j} ; j=\overline{1,19}$, the hidden neurons;

- $Y_{1}$, the output neuron;
- $W_{j i}^{k} ; i=\overline{1,5} ; j=\overline{1,19}, k=\overline{2,3}$, the weights of connections between the neuron $i$ placed in layer number $k-1$ and neuron $j$ placed in layer $k$;

- $f_{k} ; k=\overline{2,3}$, the activation function corresponding to the layer $\mathrm{k}, k=\overline{2,3}$,the neural network is working in the following way:

For the layer 1 (input), the input vector is $R=\left(R_{1}, R_{2}, R_{3}\right.$, $\left.R_{4}, R_{5}\right)$

For the layer 2 (hidden): $H_{j}=f\left(\sum_{i=1}^{5} R_{i} w_{j i}^{2}\right)$; $j=\overline{1,19}$

For the layer 3 (output): $Y_{1}=f\left(\sum_{j=1}^{19} H_{j} w_{1 j}^{3}\right)$

The number of hidden nodes is determined by the model's complexity. As it is showed in Figure no. 1, entries in the system include ratios R1, R2, R3, R4 and R5 which, after the model building process, are given different weights. Every ratio has assigned one node in 
the network. Each of the 19 nodes of the hidden layer is connected to all input and output nodes. The output layer contains a single node (Y1), which is the overall liquidity ratio.

The first step for building the model is the training period, which is the learning process when the weights are given the optimal values. Our model uses a supervised learning process because it is based on a pair of training data consisting of an input vector (R1, $R 2, R 3, R 4, R 5$ ) and a desired output $Y_{1}$. The learning method used in the model is backpropagation. The goal of the algorithm is to find the proper function that can give the right output, based on the input vector. The network's training period tries to gather knowledge about the studied model. During the training period, the algorithms determine the weight of each node and the type of relationship - direct or reverse - between them. During the storage of knowledge, the network tries to minimize the errors determined by the difference between the values provided by the model and the target values, changing the weights. Taken together, the sets of input values that consist of the five financial indicators values for the years 2010, 2011, 2012 and 2013 is the information that is used by the neural network to change its structure.

The result of the test (see Figure no. 2) confirms the accuracy and predictive power of the designed model.

Figure no. 2. General liquidity ratio, comparison between the value predicted by the neural model and the target value

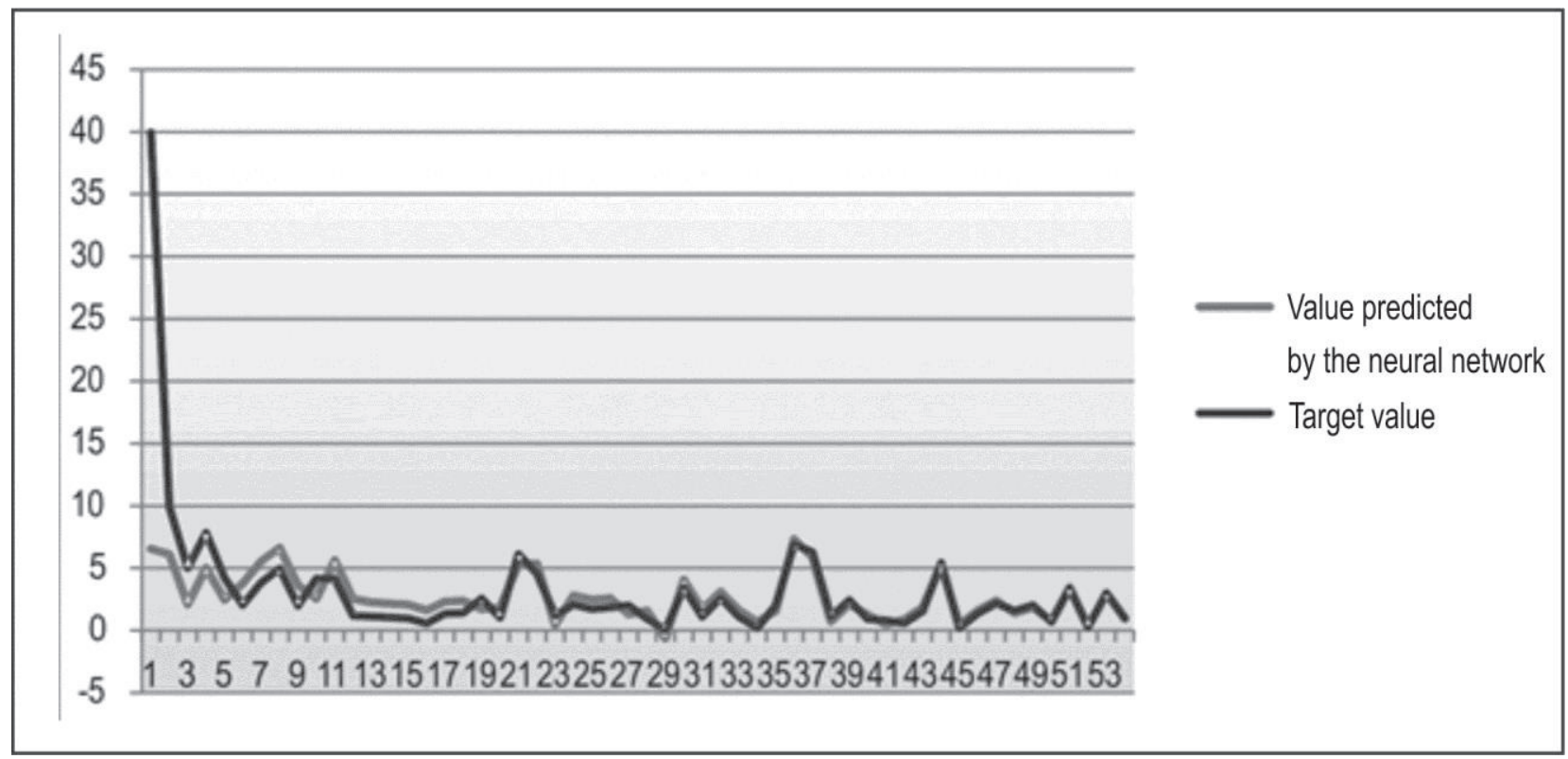

Source: own processing in Excel and PyBrain

To implement the proposed model, we used the open source application PyBrain (Tom et al, 2010) built in the Python programming language. The training error value is set to 0.0001 , with a learning rate of 0.05 , using a total of 19,944 iterations for the learning stage. Following the stored knowledge, we tested the model using the appropriate database comparing forecast values for the year 2014 with target values for the neural network. The process is repeated using the neurons from theal hidden layers. It was found that the algorithm gave an accurate model which can be used in the prediction analysis.

\subsection{Building a neural network model for predicting the overall solvency ratio}

The solvency or the patrimonial solidity of an entity is its ability to pay on the due dates its long-term debts and interests. In our application, we built a neural network to predict the overall solvency ratio (see Figure no. 3). 
Where:

- R1 (Fixed assets ratio) $=$ fixed assets/total assets

- $\quad$ R2 (Overall financial autonomy ratio) = shareholders' equity/total liabilities
- $\mathrm{R} 3$ (Overall liquidity ratio) $=$ current assets/current liabilities

- $\quad$ Y2 (Overall solvency ratio) $=$ total assets/total liabilities

Figure no. 3. The neural network model to predict the overall solvency ratio

Fixed assets ratio

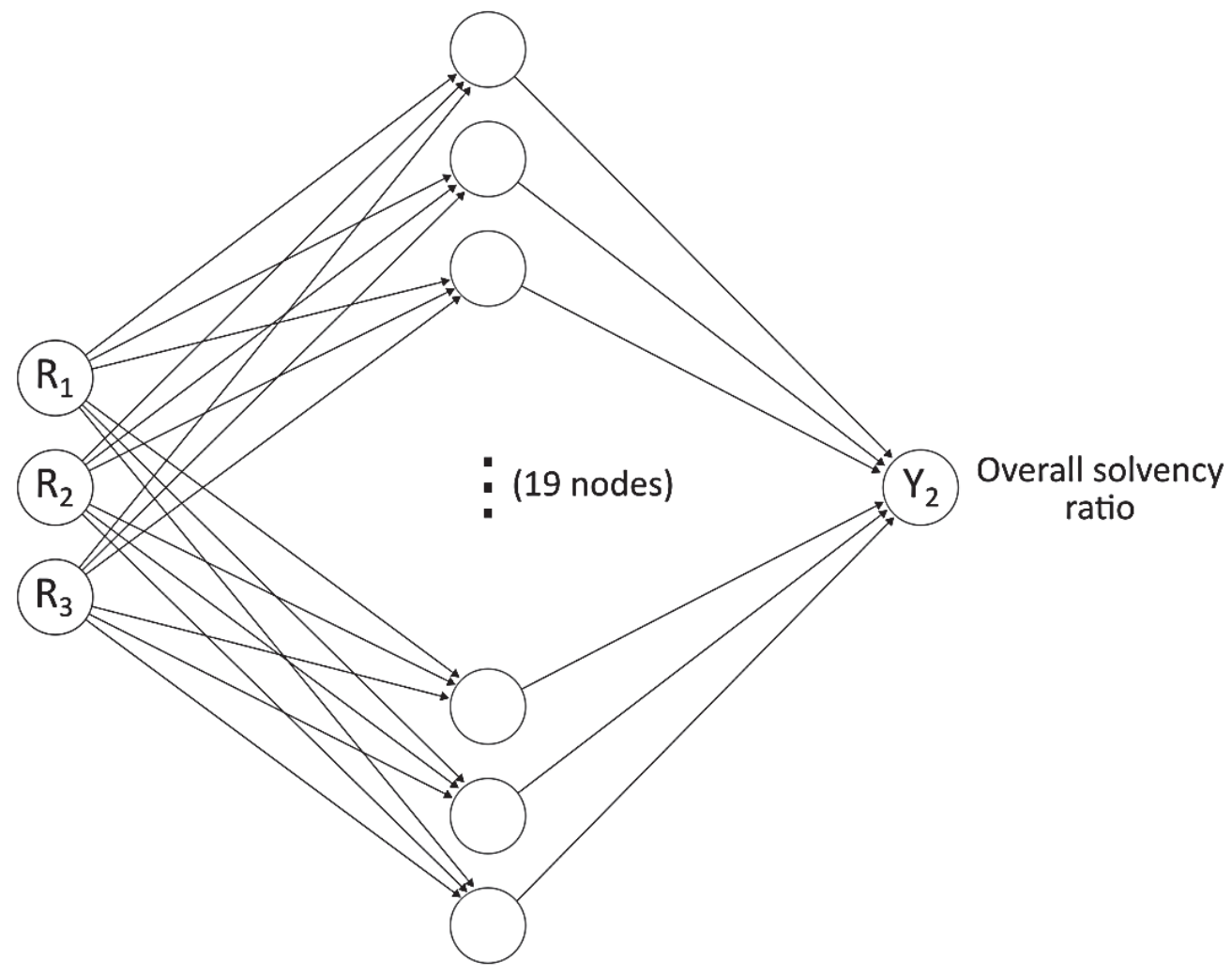

Overall financial autonomy ratio

Overall liquidity ratio

$$
\begin{gathered}
\text { layer with } \\
\text { hidden nodes }
\end{gathered}
$$

layer with output nodes

Source: own projection

As shown in Figure no. 4, there are 23 nodes, three input nodes, one output corresponding to the general solvency ratio $\mathrm{Y} 1$, and 19 hidden nodes (Prodan-Palade, 2016). The inputs in the system include ratios R1, R2,
R3. For each of them there is one node in the network. During the model building process, they receive different weights. 


\section{Figure no. 4. The solvency ratio, general comparison of the value predicted by the neural model and the} target

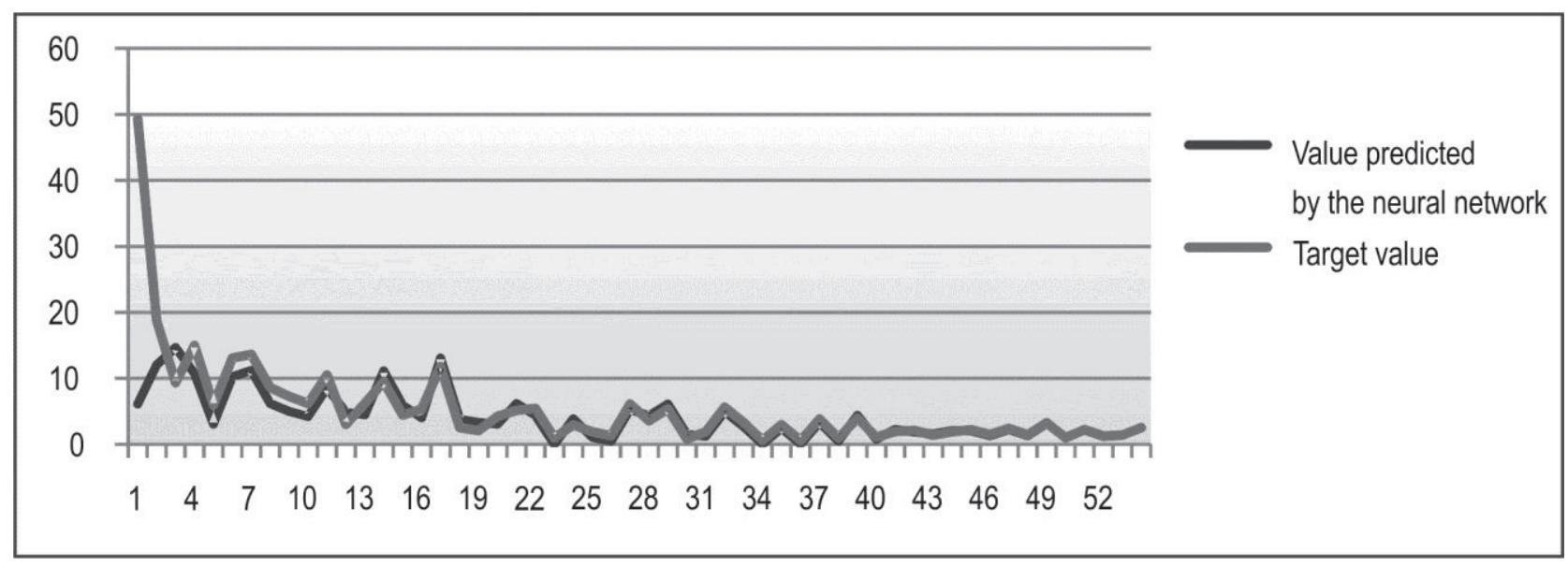

Source: own processing in Excel and PyBrain

An important aspect of neural networks is the convergence error that means minimizing the differences between the model output vector obtained by learning and the target vector containing the set of a priori given values. When the inputs values cannot explain the output target values, namely there is no correlation between them, the network cannot build the neural model and the recorded errors don't converge. Our network is convergent and the errors reach a local minimum (see Figures no. 5 and 6).

\section{Figure no. 5. The evolution of errors recorded during the 19,944 training steps}

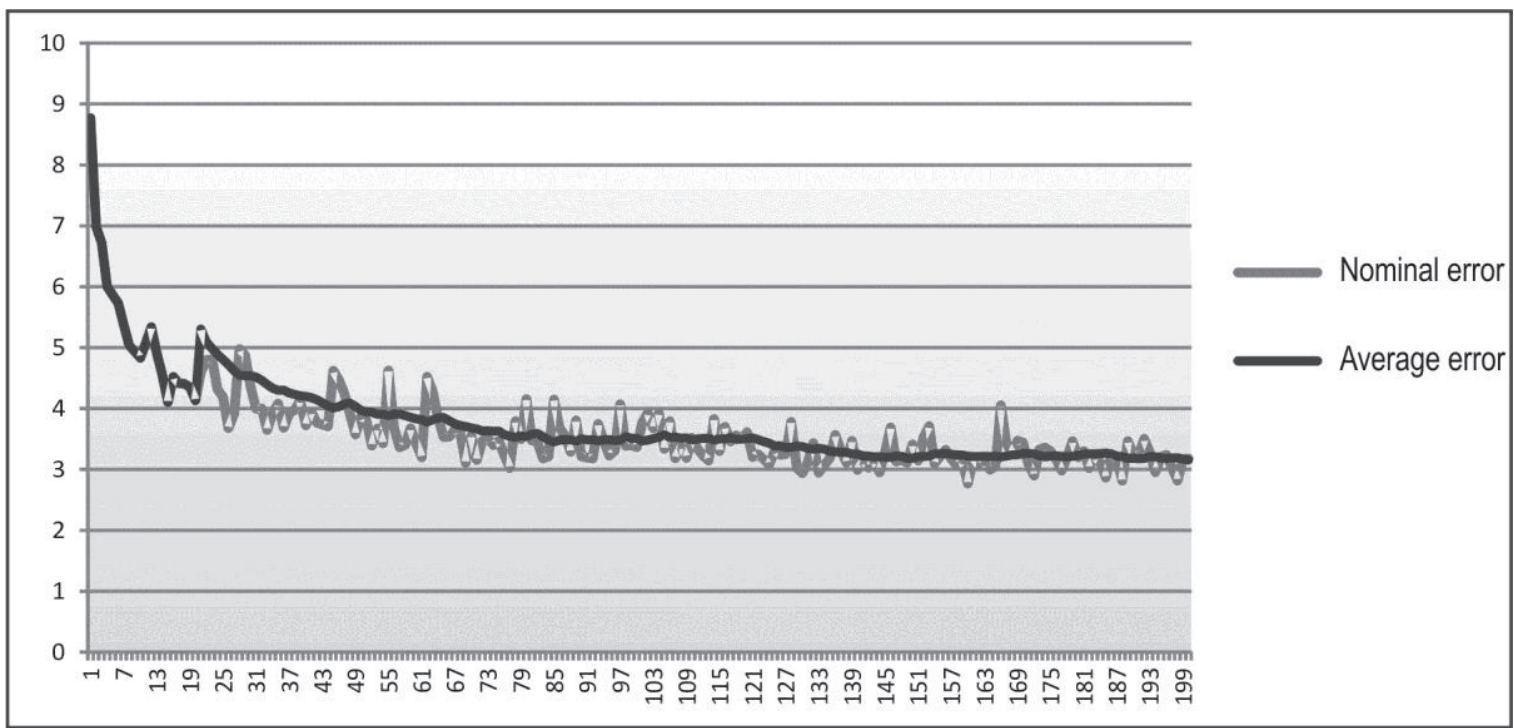

Source: own processing in Excel and PyBrain 


\section{Figure no. 6. The evolution of moving average errors during the 19,944 training steps}

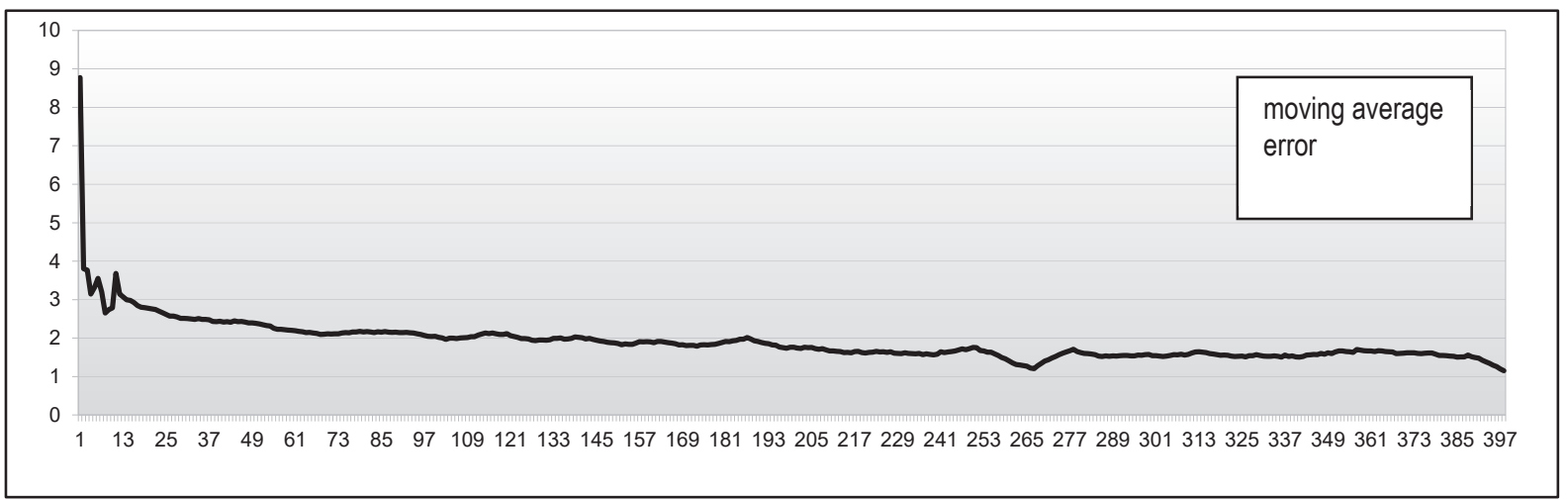

Source: own processing in Excel and PyBrain

\section{Conclusions and perspectives on the use of neural networks in economy}

The purpose of our research was to develop two neural networks of backpropagation type, a widely used technique, to predict the overall liquidity and solvency ratios of the entity. We tested each model's accuracy by comparing the output of the predicted model with a set of target values taken from the audited financial statements of entities listed on BSE. The novelty of the research is that we used a sample of Romanian entities and for our investigation we used the recent available financial accounting information for the years from 2010 to 2014. With the mentioned tools, we built the neural networks using a combination of financial indicators which were chosen based on the specialized literature and own reasoning. The research is justified by the ever increasing request for implementation of performance algorithms that can make a correct prediction of the firms' evolution on the rapidly growing contemporary markets. The accuracy of the predictions is impressive, proving once again that information technologies in symbiosis with financial information produce value for the entities and constitute basic elements of modern management.

Due to a broad spectrum of factors that influence a firm's activity, the prediction of its evolution is a difficult process. To obtain reliable results, the analysts must use complex models and a large amount of data. If the forecasted results differ significantly from the values recorded in annual reports, they represent an impediment to the management process. The risks are magnified and the entity loses its credibility for the investors. Therefore, the analysis and prediction activity play a very important role, influencing the company's relationship with its stakeholders. All these elements justify the need to develop modern and efficient methodologies of analysis and prediction of the risk of bankruptcy.

In the research works, the financial risk is defined by several indicators, depending on the context of the investigation. For banks, it can suggest the entity's inability to pay debts at maturity, while for the stock exchanges companies that register losses or negative equity for three consecutive financial exercises have high financial risk (Shang, 2015). At the same time, the suppliers take decisions based on the solvency, liquidity and going concern ratios of the entity, usually pursuing a less time horizon compared to the financial creditors. From the corporate governance's point of view, risk reduction involves increasing the liquidity and solvency and making the best decisions to ensure a financial autonomy and a competitive favorable position on the market. Therefore, we consider appropriate the prediction of these indicators, namely the overall liquidity and solvency ratios. For a proper risk assessment, we need to analyze and interpret the significant aspects of the entity's business activity and the ability to predict any unforeseen future events that may occur. An example is the financing activity, which is an important part of the investment and development process. It is an essential part of the economic policy for a company. Financing 
decisions must be based on the information provided by economic and financial analysis. If an entity has provided more alternatives for financing, the manager will have to choose the best option that fits the business needs, according to its specific activity and long-term strategies. Since long-term financial resources are part of the permanent capital of the entity, being in direct connection with the entity's financial mechanisms in the long term, the selection of the most efficient variant is made by following a detailed review process.

Conventional techniques for risk prediction have some drawbacks. For example, in the case of the Z score function, there is no theoretical basis of strict linear dependence of the variables used in the regression model. The application of fuzzy logic, which works with logical values in the range zero and one, show more accuracy in prediction algorithms, but requires advanced knowledge and experience from the practitioners. The neural networks learn by themselves, but they need experience based on the examples provided at the input, without specifying certain modeling functions and without resorting to specialist knowledge.

Research papers published in the field show that a welltrained neural network can predict the financial risk with great accuracy, recording higher performance than the multivariate linear regression algorithms (Coats and Fant, 1993; Shang et al., 2015). They can be properly approximated by non-linear functions, using neurons placed in the hidden layers and weighting the links between nodes. Neural networks offer valuable solutions to various complex issues of corporates activities and they are very useful tools for stock exchanges, investors, managers and financiers.

As future research, we plan to use neural networks to detect fraud in financial reporting. The model that we recommend for further work should use values of certain financial ratios predicted by the neural network, which can be compared with the target values taken from annual and audited reports. Significant discrepancies may be a signal of fraudulent reporting activity and the auditors can enhance their control over these items. The backpropagation method which is used in this paper can be replaced by other methods (Enăchescu, 2009). At the same time, for predicting bankruptcy risk we have to consider other financial and non-financial variables related to the governance of an entity.

We should mention some research limitations: the sample was composed of only 55 entities which were analyzed over a short time period. The efficiency of neural networks increases proportionally to the amount of input data. It could be interesting to study all the Romanian entities, including those which are not listed on the Bucharest Stock Exchange. To provide an overview of the Romanian companies, we mention that on 31 December 2015 there were 773,781 active firms registered in Romania. A comprehensive study, taking a sample of all these entities may be of particular interest for the economic environment of our country.

\section{REFERENCES}

1. Ahangar, A.G., Yahyazadehfar, M. and Pournaghshband, H. (2010), The comparison of methods artificial neural network with linear regression using specific variables for prediction stock price in Tehran Stock Exchange, International Journal of Computer Science and Information Security, vol. 7, no. 2, pp. 38-46.

2. Airinei, D. and Berta, D. (2012), Semantic business intelligence - a new generation of business intelligence, Informatica Economica, vol. 16, no. 2, pp. 72-80.

3. Alborzi, M., Roodposhti, F.R. and Sabet, S. (2013), Using neural networks for forecasting operation cash flows, Interdisciplinary Journal of Contemporary Research in Business, vol. 4, no. 9, pp. 1165-1173.
4. Ardebili, M.A., Hashemi, M., Shahabi, A. and Barough, M.H. (2015), Optimized selection of stock portfolio by using the fuzzy artificial neural networks web model, ARIMA and Markowitz Model in Tehran Stock Exchange, European Online Journal of Natural and Social Sciences, vol. 4, no. 1, pp. 831-844.

5. Aydin, A.D. and Cavdar, S.C. (2015), Prediction of financial crisis with artificial neural network: An empirical analysis on Turkey, International Journal of Financial Research, vol. 6, no. 4, pp. 36, DOI 10.5430/ijfr.v6n4p36.

6. Badea (Stroie), M.L. (2013), Supporting management decisions by using artificial neural network for exchange rate prediction, Accounting and Management Information Systems, vol. 12, no. 4, pp. 578-594. 
7. Bunget, O.C. (2009), Etica and audit intern: Problematica whistleblowing-ului, Audit Financiar, vol. 7, no. 9, pp. 43-51.

8. Bunget, O.C., Blidisel, R.G., Dumitrescu, A.C. and Demian, R. (2014), Reacția auditorului financiar la provocările crizei economico-financiare, Audit Financiar, vol. 12, no. 6, pp. 3-11.

9. Coats, P.K. and Fant, L.F. (1993), Recognizing financial distress patterns using a neural network tool, Financial Management, Periodicals Archive Online, vol. 22, no. 3, pp. 142-155, DOI $10.2307 / 3665934$.

10. Enăchescu, C. (2009), Calculul neuronal, Editura „Casa Cărții de Ştiință”, Cluj-Napoca.

11. Glasserman, P. and Young, H.P. (2013), How likely is contagion in financial networks? Discussion Papaer Series, University of Oxford, Department of Economics, DOI 10.2139/ssrn.2642423.

12. Hu, J.W.-S., Yi-Chung, H. and Wen Lin, R.R. (2012). Applying neural networks to prices prediction of crude oil futures, Mathematical Problems in Engineering, vol. 2012, pp. 1-12, DOI 10.1155/2012/959040.

13. Kaastra, I. and Boyd, M. (1996), Designing a neural network for forecasting financial and economic time series, Neurocomputing, vol. 10, no. 3, pp. 215-236, DOI 10.1016/0925-2312(95)000399.

14. Khademolqorani, S., Ali, Z.H. and Farimah, M.R. (2015), A hybrid analysis approach to improve financial distress forecasting: Empirical evidence from Iran, Mathematical Problems in Engineering, vol. 2015, pp. 1-9, DOI 10.1155/2015/178197.

15. Pradhan, R., Pathak, K.K. and Singh, V.P. (2011), Application of neural network in prediction of financial viability, International Journal of Soft
Computing and Engineering (IJSCE), vol. 1, no. 2, pp. 41-45.

16. Prodan-Palade, D. (2016), Corporate governance between performance and non-performance validated through accounting, $P h D$ Thesis, Alexandru loan Cuza University, Romania.

17. Salama, A.S. and Omar, A.A. (2014), A back propagation artificial neural network based model for detecting and predicting fraudulent financial reporting, International Journal of Computer Applications, vol. 106, no. 2, DOI 10.5120/184899521.

18. Shang, H., Huang, J., Yang, J. and Zhou, D. (2015), Predicting financial risk of Chinese listed companies in strategic emerging industries with $\mathrm{BP}$ neural network, Advances in Information Sciences and Service Sciences, vol. 7, no. 4, pp. 43-58.

19. Tjung, L.C., Kwon, O. and Tseng, K.C. (2012), Comparison study on neural network and ordinary least squares model to stocks' prices forecasting, Academy of Information and Management Sciences Journal, vol. 15, no. 1, pp. 1-35.

20. Vallini, C., Ciampi, F. and Gordini, D.N. (2009), Using artificial neural networks analysis for small enterprise default prediction modeling: statistical evidence from Italian firms. 2009 Oxford Business and Economics Conference Program, ISBN: 978-09742114-1-1.

21. Walczak, S. (2001), An empirical analysis of data requirements for financial forecasting with neural networks, Journal of Management Information Systems, vol. 17, no. 4, pp. 203-222, DOI 10.1080/07421222.2001.11045659.

22. Yildiz, B. and Yezegel, A. (2010), Fundamental Analysis with Artificial Neural Network, The International Journal of Business and Finance Research, vol. 4, no. 1, pp. 149-158. 